\title{
Effectiveness and adverse events of endoscopic clipping versus band ligation for colonic diverticular hemorrhage: a large-scale multicenter cohort study
}

\section{(이요 $\odot$}

\section{Authors}

Katsumasa Kobayashi ${ }^{1} \odot$, Naoyoshi Nagata²,3, Yohei Furumoto ${ }^{1}$, Atsushi Yamauchi $^{4} \odot$, Atsuo Yamada ${ }^{5}$, Jun Omori6, Takashi Ikeya7, Taiki Aoyama ${ }^{8}$, Naoyuki Tominaga ${ }^{9}$, Yoshinori Sato ${ }^{10}$, Takaaki Kishino ${ }^{11}$, Naoki Ishii ${ }^{12}$, Tsunaki Sawada ${ }^{13}$, Masaki Murata ${ }^{14}$, Akinari Takao ${ }^{15}$, Kazuhiro Mizukami ${ }^{16}$, Ken Kinjo ${ }^{17}$, Shunji Fujimori ${ }^{18}$, Takahiro Uotani ${ }^{19}$, Minoru Fujita ${ }^{20}$, Hiroki Sato ${ }^{21} \odot$, Sho Suzuki ${ }^{22}$, Toshiaki Narasaka ${ }^{23,24}$, Junnosuke Hayasaka ${ }^{25}$, Mitsuru Kaise ${ }^{6}$, CODE BLUE-J study collaborators

CODE BLUE-J study collaborators

Tomohiro Funabiki ${ }^{26,27}$, Yuzuru Kinjo ${ }^{28}$, Akira Mizuki ${ }^{29}$, Shu Kiyotoki ${ }^{30}$, Tatsuya Mikami ${ }^{31}$, Ryosuke Gushima ${ }^{32}$, Hiroyuki Fujii ${ }^{33}$, Yuta Fuyuno ${ }^{34}$, Naohiko Gunji ${ }^{35}$, Yosuke Toya ${ }^{36}$, Kazuyuki Narimatsu ${ }^{37}$, Noriaki Manabe ${ }^{38}$, Koji Nagaike $^{39}$, Tetsu Kinjo ${ }^{40}$, Yorinobu Sumida ${ }^{41}$, Sadahiro Funakoshi ${ }^{42}$, Kana Kawagishi ${ }^{43}$, Tamotsu Matsuhashi ${ }^{44}$, Yuga Komaki $^{45}$, Kuniko Miki², Kazuhiro Watanabe ${ }^{3}$, Naoki Kitano ${ }^{1}$, Shu Kato ${ }^{1}$, Shun Sakai ${ }^{1}$, Eri Oshina ${ }^{1}$, Tomohiro Mochida ${ }^{1}$, Yukito Okura ${ }^{1}$, Mana Matsuoka ${ }^{1}$, Takahito Nozaka ${ }^{1}$, Ayako Sato ${ }^{1}$, Masato Yauchi ${ }^{1}$, Taichi Matsumoto ${ }^{1}$, Toru Asano $^{1}$

Institutions

1 Department of Gastroenterology, Tokyo Metropolitan Bokutoh Hospital, Tokyo, Japan

2 Department of Gastroenterological Endoscopy, Tokyo Medical University, Tokyo, Japan

3 Department of Gastroenterology and Hepatology, National Center for Global Health and Medicine, Tokyo, Japan

4 Department of Gastroenterology and Hepatology, Kitano Hospital, Tazuke Kofukai Medical Research Institute, Osaka, Japan

5 Department of Gastroenterology, Graduate School of Medicine, The University of Tokyo, Tokyo, Japan

6 Department of Gastroenterology, Nippon Medical School, Graduate School of Medicine, Tokyo, Japan

7 Department of Gastroenterology, St. Luke's International University, Tokyo, Japan

8 Department of Gastroenterology, Hiroshima City Asa Citizens Hospital, Hiroshima, Japan

9 Department of Gastroenterology, Saga Medical Center Koseikan, Saga, Japan

10 Division of Gastroenterology and Hepatology, Department of Internal Medicine, St Marianna University School of Medicine, Kanagawa, Japan

11 Department of Gastroenterology and Hepatology, Center for Digestive and Liver Diseases, Nara City Hospital, Nara, Japan

12 Department of Gastroenterology, Tokyo Shinagawa Hospital, Tokyo, Japan

13 Department of Endoscopy, Nagoya University Hospital, Aichi, Japan

14 Department of Gastroenterology, National Hospital Organization Kyoto Medical Center, Kyoto, Japan
15 Department of Gastroenterology, Tokyo Metropolitan Cancer and Infectious Diseases Center Komagome Hospital, Tokyo, Japan

16 Department of Gastroenterology, Oita University, Oita, Japan

17 Department of Gastroenterology, Fukuoka University Chikushi Hospital, Fukuoka, Japan

18 Department of Gastroenterology, Chiba Hokusoh Hospital, Nippon Medical School, Chiba, Japan

19 Department of Gastroenterology, Japanese Red Cross Shizuoka Hospital, Shizuoka, Japan

20 Division of Endoscopy and Ultrasonography, Department of Clinical Pathology and Laboratory Medicine, Kawasaki Medical School General Medical Center, Okayama, Japan

21 Division of Gastroenterology, Graduate School of Medical and Dental Sciences, Niigata University, Niigata, Japan

22 Department of Gastroenterology and Hepatology, Center for Digestive Disease and Division of Endoscopy, University of Miyazaki Hospital, Miyazaki, Japan

23 Department of Gastroenterology, University of Tsukuba, Ibaraki, Japan

24 Division of Endoscopic Center, University of Tsukuba Hospital, Ibaraki Japan

25 Department of Gastroenterology, Toranomon Hospital, Tokyo, Japan

26 Department of Emergency Medicine, Fujita Health University Hospital, Aichi, Japan

27 Emergency and Critical Care Center, Saiseikai Yokohama Tobu Hospital, Kanagawa, Japan 
28 Department of Gastroenterology, Naha City Hospital, Okinawa, Japan

29 Department of Internal Medicine, Tokyo Saiseikai Central Hospital, Tokyo, Japan

30 Department of Gastroenterology, Shuto General Hospital, Yamaguchi, Japan

31 Division of Endoscopy, Hirosaki University Hospital, Aomori, Japan

32 Department of Gastroenterology and Hepatology, Graduate School of Medical Sciences, Kumamoto University, Kumamoto, Japan

33 Department of Gastroenterology and Hepatology, National Hospital Organization Fukuokahigashi Medical Center, Fukuoka, Japan

34 Department of Medicine and Clinical Science, Graduate School of Medical Sciences, Kyushu University, Fukuoka, Japan

35 Department of Gastroenterology, Fukushima Medical University, Fukushima, Japan

36 Division of Gastroenterology, Department of Internal Medicine, Iwate Medical University, Iwate, Japan

37 Department of Internal Medicine, National Defense Medical College, Saitama, Japan

38 Division of Endoscopy and Ultrasonography, Department of Clinical Pathology and Laboratory Medicine, Kawasaki Medical School, Okayama, Japan

39 Department of Gastroenterology and Hepatology, Suita Municipal Hospital, Osaka, Japan

40 Department of Endoscopy, University of the Ryukyus Hospital, Okinawa, Japan

41 Department of Gastroenterology, National Hospital Organization Kyushu Medical Center, Fukuoka, Japan

42 Department of Gastroenterological Endoscopy, Fukuoka University Hospital, Fukuoka, Japan

43 Department of Gastroenterology, Kitasato University, School of Medicine, Kanagawa, Japan

44 Department of Gastroenterology and Neurology, Akita University Graduate School of Medicine, Akita, Japan

45 Digestive and Lifestyle Diseases, Kagoshima University Graduate School of Medical and Dental Sciences, Kagoshima, Japan

submitted 25.5.2021

accepted after revision $\quad 1.12 .2021$

published online 24.11.2021

Bibliography

Endoscopy 2022; 54: 735-744

DOI 10.1055/a-1705-0921

ISSN 0013-726X

(c) 2021. The Author(s).
This is an open access article published by Thieme under the terms of the Creative Commons Attribution-NonDerivative-NonCommercial License, permitting copying and reproduction so long as the original work is given appropriate credit. Contents may not be used for commercial purposes, or adapted, remixed, transformed or built upon. (https://creativecommons.org/licenses/by-nc-nd/4.0/)

Georg Thieme Verlag KG, Rüdigerstraße 14,

70469 Stuttgart, Germany

\& Tables $1 \mathrm{~s}, 2 \mathrm{~s}$, Fig, $1 \mathrm{~s}$

Supplementary material is available under

https://doi.org/10.1055/a-1705-0921

Corresponding author

Naoyoshi Nagata, MD PhD, Department of

Gastroenterological Endoscopy, Tokyo Medical University, 6-

7-1, Nishishinjuku, Shinjuku-ku, Tokyo 160-0023, Japan

nnagata_ncgm@yahoo.co.jp

\section{ABSTRACT}

Background Prior studies have shown the effectiveness of both endoscopic band ligation (EBL) and clipping for colonic diverticular hemorrhage $(\mathrm{CDH})$ but have been small and conducted at single centers. Therefore, we investigated which was the more effective and safe treatment in a multicenter long-term cohort study.

Methods We reviewed data for 1679 patients with $\mathrm{CDH}$ who were treated with EBL $(n=638)$ or clipping $(n=1041)$ between January 2010 and December 2019 at 49 hospitals across Japan (CODE BLUE-J study). Logistic regression analysis was used to compare outcomes between the two treatments.

Results In multivariate analysis, EBL was independently associated with reduced risk of early rebleeding (adjusted odds ratio $[O R]$ 0.46; $P<0.001$ ) and late rebleeding (adjusted OR 0.62; $P<0.001)$ compared with clipping. These significantly lower rebleeding rates with EBL were evident regardless of active bleeding or early colonoscopy. No significant differences were found between the treatments in the rates of initial hemostasis or mortality. Compared with clipping, EBL independently reduced the risk of needing interventional radiology (adjusted OR $0.37 ; P=0.006$ ) and prolonged length of hospital stay (adjusted OR 0.35; $P<$ 0.001 ), but not need for surgery. Diverticulitis developed in one patient $(0.16 \%)$ following EBL and two patients $(0.19 \%)$ following clipping. Perforation occurred in two patients $(0.31 \%)$ following EBL and none following clipping.

Conclusions Analysis of our large endoscopy dataset suggests that EBL is an effective and safe endoscopic therapy for $\mathrm{CDH}$, offering the advantages of lower early and late rebleeding rates, reduced need for interventional radiology, and shorter length of hospital stay. 


\section{Introduction}

The most common cause of acute lower gastrointestinal bleeding is colonic diverticular hemorrhage (CDH) [1]. Given that $\mathrm{CDH}$ with stigmata of recent hemorrhage (SRH) treated conservatively has a high 30 -day rebleeding rate $(65.8 \%)$ [2], endoscopic treatment is indicated for definitive CDH with SRH [1]. Several endoscopic treatment techniques for $\mathrm{CDH}$ have been reported, including epinephrine injection, contact thermal therapy, endoscopic clipping, endoscopic band ligation (EBL), endoscopic detachable snare ligation, and over-the-scope clipping $[1,3]$. Among these, endoscopic clipping is the most common because of its simplicity and low invasiveness $[1,4-10]$, and is the most frequently performed technique in Japan [11].

$\mathrm{EBL}$ is, however, becoming more widely performed because it allows for occlusion of SRH and any underlying arteries [4-6, 12-14]. Although a recent meta-analysis reported lower early and late rebleeding rates with EBL compared with clipping [10], the number of cases in each study included in the analysis was small, with at most 101 cases per treatment method and only 790 cases analyzed in total. In addition, these were all single-center studies, so their results may suffer from bias in relation to the treatment strategies and techniques used in each study setting. Importantly, relatively few of the studies investigated the long-term effectiveness of the various endoscopic treatments for $\mathrm{CDH}$ [1], and the rates of diverticulitis and perforation, which have been reported as adverse events (AE) of endoscopic treatment for $\mathrm{CDH}$, could not be confirmed by the systematic review because of the small number of cases analyzed.

To address these issues, we conducted a multicenter longterm cohort study in Japan and report here the short- and long-term effectiveness of clipping versus EBL for $\mathrm{CDH}$, as well as the AEs associated with them.

\section{Methods}

\section{Patients and study design}

The dataset analyzed in this study is from the CODE BLUE-J study (COlonic DivErticular Bleeding Leaders Update Evidence from multicenter Japanese study), a retrospective multicenter cohort study that was conducted at 49 hospitals across Japan $[15,16]$. From among patients emergently hospitalized for acute hematochezia between January 2010 and December 2019, a total of 10342 patients were enrolled. The ethics committees and institutional review boards of all 49 participating hospitals approved this study being conducted with the optout method (Table $1 \mathrm{~s}$, see online-only Supplementary material). Of these 10342 patients, 2020 were diagnosed with definitive CDH based on the presence of SRH ( $\vee$ Fig. 1a, b), with the source of the bleeding being identified as active bleeding, a non-bleeding visible vessel, or an adherent clot [1]. Among these patients, the 1041 patients who were treated with clipping ( $\vee$ Fig. 1c) and the 638 who were treated with EBL ( $\bullet$ Fig. 1d) were analyzed in this study ( $\bullet$ Fig. 2).

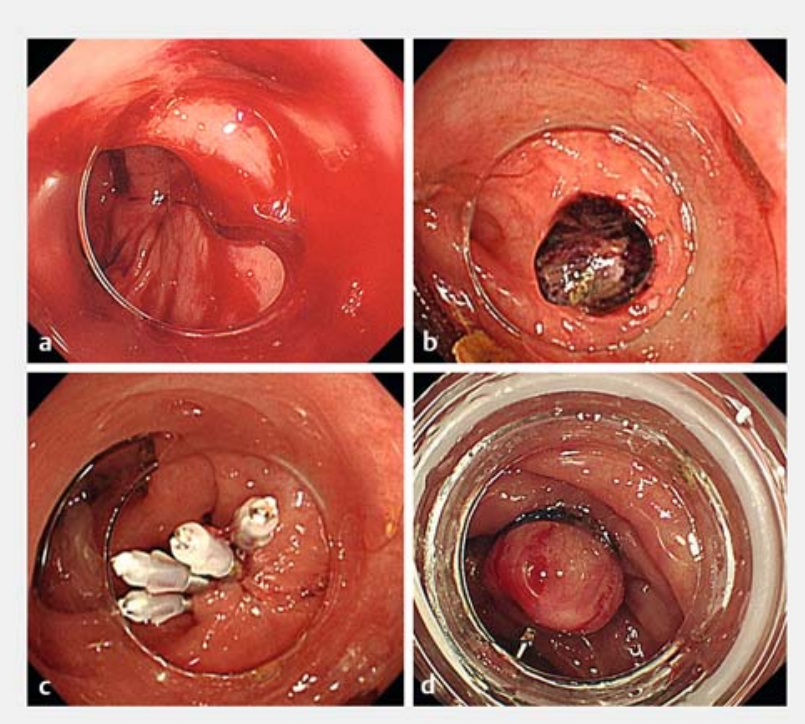

- Fig. 1 Example endoscopic appearances of: a the stigmata of recent hemorrhage as evidenced by active bleeding; $\mathbf{b}$ the stigmata of recent hemorrhage as evidenced by adherent clot; c endoscopic clipping (indirect placement of endoclips) for colonic diverticular hemorrhage; $\mathbf{d}$ endoscopic band ligation for colonic diverticular hemorrhage.

\section{Variables and clinical outcomes}

A total of 72 items were collected for evaluation from the electronic medical records and endoscopy database $[15,16]$. Data on baseline characteristics included age, sex, presenting symptoms, vital signs, laboratory data, past history, co-morbidities, medications, computed tomography (CT) and endoscopic findings, and endoscopic factors. Co-morbidities were assessed using the modified Charlson co-morbidity index (CCl), consisting of 19 items from the original $\mathrm{CCl}$ [17] and two additional items (hypertension and hyperlipidemia). The presence of extravasation was evaluated using contrast-enhanced CT. The detailed endoscopic factors evaluated included timing of colonoscopy, bowel preparation, distal-attachment cap use, water-jet scope use, SRH type (active bleeding vs. non-active bleeding), and location. The left-sided colon was defined as the descending and sigmoid colon and the rectum, and right-sided colon as all other locations. The clipping and EBL techniques used have been described in detail elsewhere [4-9, 12-14].

The outcome of most interest was the rate of early rebleeding. Early rebleeding was defined as rebleeding within 30 days of endoscopic treatment for $\mathrm{CDH}$. The other outcomes evaluated were the rate of late rebleeding, the success rate of initial hemostasis, mortality after endoscopic treatment (within 30 days and 1 year), thromboembolism during hospitalization, need for interventional radiology (IVR) or surgery, red blood cell transfusion, length of hospital stay (LOS) after endoscopic treatment, and endoscopically relevant AEs.

Late rebleeding was defined as rebleeding within 1 year [ 1 , 4], which was determined from the clinical data collected during follow-up. Rebleeding was defined as the presence of significant amounts of fresh, bloody, or wine-colored stools after 
Patients admitted for acute hematochezia $(n=10342)$

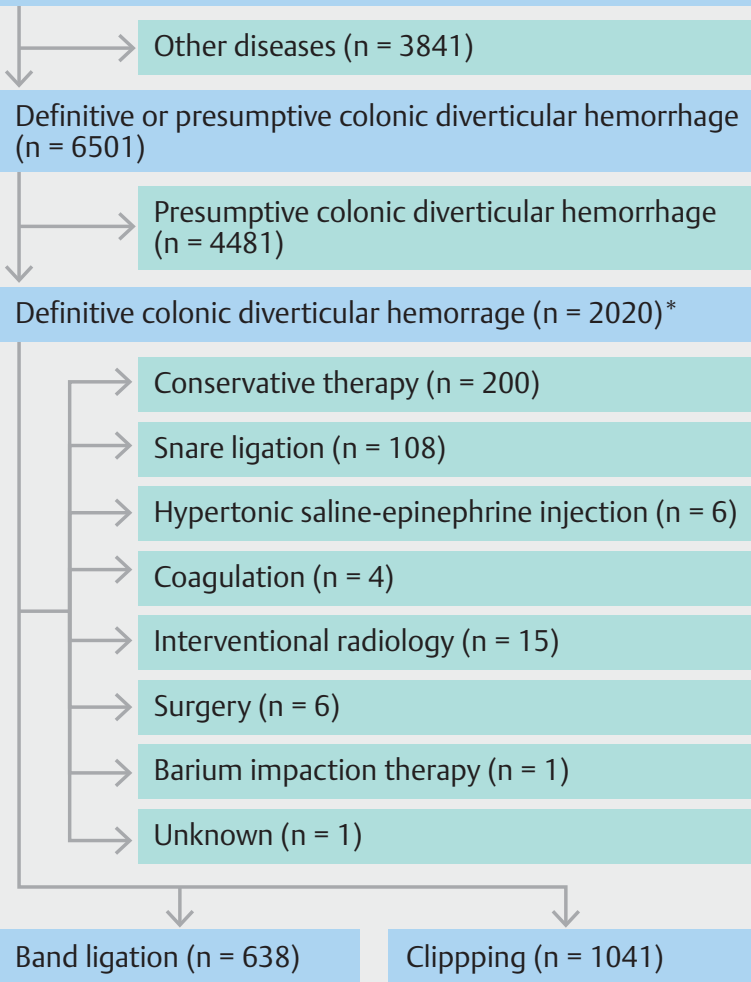

- Fig. 2 Flow chart of patients in this study. ${ }^{*}$ The high identification rate of stigmata of recent hemorrhage, about one-third of the 6501 patients diagnosed with colonic diverticular hemorrhage, may be associated with the high early colonoscopy rate (64.4\% underwent early colonoscopy [within 24 hours of admission]), high preparation rate $(81.4 \%$ received polyethylene glycol or glycerin ene$\mathrm{ma}$ ), and high levels of endoscopic device use (distal attachment used in $77.1 \%$; water-jet device used in $79.3 \%$ ).

initial hemostasis. Rebleeding included events both during hospitalization and after discharge. Thromboembolism included a cardiovascular event, cerebrovascular event, pulmonary embolism, or deep vein thrombosis. Endoscopically relevant AEs included perforation and diverticulitis. Perforation was diagnosed based on clinical signs and symptoms (e.g. abdominal pain) and CT findings (e. g. free intraperitoneal air) [18]. Diverticulitis was diagnosed based on symptoms such as abdominal pain and fever, CT findings, and blood test results (e. g. elevated C-reactive protein) [19].

\section{Statistical analysis}

Categorical data were compared using the $x^{2}$ test or Fisher's exact test as appropriate. Continuous data were compared using the Mann-Whitney $U$ test. The association between endoscopic treatment and clinical outcomes was analyzed using univariate and multivariate logistic regression models.

The multivariate analysis was adjusted for age, sex, and the following 15 factors that were potentially clinically important variables, most of which were found to have at least borderline significance $(P<0.10)$ on univariate analysis: current drinker, systolic blood pressure $\leq 100 \mathrm{mmHg}$, loss of consciousness, hemoglobin $<12 \mathrm{~g} / \mathrm{dL}$, white blood cell $>10000 / \mu \mathrm{L}$, blood urea nitrogen $>25 \mathrm{mg} / \mathrm{dL}$, antiplatelet use, anticoagulant use, corticosteroid use, extravasation on CT, location of the SRH, early colonoscopy, bowel preparation, use of distal attachment, and use of water-jet scope. In the analysis of need for IVR, multivariate analysis was adjusted for age, sex, and four factors that were found to be significant $(P<0.01)$ on univariate analysis between the groups because at least 10 events per confounder were needed [20]. Although this dataset has very few missing values despite its retrospective design ( $\bullet$ Table 1$)$, we considered the effect of missing values on the outcomes. We used multiple imputation to handle missing values, and compared the results with the complete case analysis [21,22].

In subgroup analysis, the rebleeding risk was also compared between EBL and clipping, using univariate and multivariate logistic regression models, according to SRH type (active bleeding vs. non-active bleeding), timing of colonoscopy (early colonoscopy [within 24 hours of admission] vs. non-early colonoscopy), and location of the SRH (right vs. left). Multivariate analysis in the subgroup analysis was adjusted for age, sex, and factors found to be significantly different between the two groups $(P<0.05)$.

A two-sided $P$ value of $<0.05$ was considered statistically significant. All statistical analysis was performed using STATA v.16 (StataCorp., College Station, Texas, USA).

\section{Results}

\section{Patient characteristics and clinical outcomes}

Characteristics of the patients who underwent band ligation or clipping $(n=1679)$ are shown in $>$ Table 1 . Some variables were found to be significantly different between the groups, including current drinker, systolic blood pressure $\leq 100 \mathrm{mmHg}$, loss of consciousness, hemoglobin $<12 \mathrm{~g} / \mathrm{dL}$, blood urea nitrogen $>25$ $\mathrm{mg} / \mathrm{dL}$, antiplatelet use, corticosteroid use, extravasation on $\mathrm{CT}$, and some endoscopic factors.

As shown in $>$ Table 2, in multivariate analysis, no significant differences were found between the two treatments for endoscopic hemostasis rate. Compared with clipping, EBL was independently associated with reduced risk of early rebleeding (adjusted odds ratio [OR] 0.46; $95 \% \mathrm{Cl} 0.34-0.62 ; P<0.001)$, and late rebleeding (adjusted OR $0.62 ; 95 \% \mathrm{Cl} 0.49-0.79 ; P<$ $0.001)$. Kaplan-Meier analysis revealed a significantly lower probability of rebleeding with EBL than with clipping during the mean follow-up period of 13.3 months (log rank test, $P<$ 0.001) (Fig. $1 \mathrm{~s}$ ).

No significant differences were noted in mortality within 30 days or 1 year of endoscopic treatment, or in-hospital thromboembolism ( $\vee$ Table 2$)$. Compared with clipping, EBL independently reduced the risk of needing IVR (adjusted OR 0.37; $95 \% \mathrm{Cl} 0.19-0.76 ; P=0.006$ ) and prolonged LOS (adjusted OR $0.35 ; 95 \% \mathrm{Cl} 0.27-0.45 ; P<0.001)$, whereas the need for surgery and the need for transfusion were not significantly different between the two treatments. There were no significant dif- 
- Table 1 Characteristics of patients who underwent endoscopic band ligation or clipping for colonic diverticular hemorrhage.

\begin{tabular}{|c|c|c|c|}
\hline & Band ligation $(n=638)$ & Clipping ( $n=1041$ ) & $P$ value \\
\hline Age $\geq 70$ years & $397(62.2)$ & $662(63.6)$ & 0.57 \\
\hline Sex, male & $444(69.6)$ & $735(70.6)$ & 0.66 \\
\hline Body mass index $>25 \mathrm{~kg} / \mathrm{m}^{2}$ & $171(28.0)$ & $287(29.6)$ & 0.49 \\
\hline Current drinker & $308(56.1)$ & $451(50.1)$ & 0.03 \\
\hline Current smoker & $106(18.6)$ & $151(16.5)$ & 0.29 \\
\hline Performance status $\geq 2$ & $63(9.9)$ & $92(8.8)$ & 0.47 \\
\hline Systolic blood pressure $\leq 100 \mathrm{mmHg}$ & $57(9.0)$ & $134(13.2)$ & 0.01 \\
\hline Pulse $\geq 100$ beats per minute & $120(19.1)$ & $220(21.7)$ & 0.20 \\
\hline Loss of consciousness & $57(8.9)$ & $59(5.7)$ & 0.01 \\
\hline \multicolumn{4}{|l|}{ Laboratory data } \\
\hline - Hemoglobin $<12 \mathrm{~g} / \mathrm{dL}$ & $330(51.7)$ & $604(58.0)$ & 0.01 \\
\hline 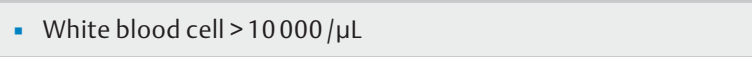 & $68(10.7)$ & $143(13.7)$ & 0.07 \\
\hline - Platelets $<15 \times 10^{4} / \mu \mathrm{L}$ & $85(13.3)$ & $152(14.6)$ & 0.47 \\
\hline - Albumin $<3.0 \mathrm{~g} / \mathrm{dL}$ & $39(6.3)$ & $79(7.9)$ & 0.22 \\
\hline - Blood urea nitrogen $>25$ mg/dL & $110(17.3)$ & $242(23.4)$ & 0.003 \\
\hline History of colorectal surgery & $38(6.0)$ & $57(5.5)$ & 0.68 \\
\hline History of colonic diverticular hemorrhage & $260(40.8)$ & $385(37.0)$ & 0.12 \\
\hline Modified Charlson co-morbidity index $\geq 2$ & $346(54.2)$ & $593(57.0)$ & 0.27 \\
\hline \multicolumn{4}{|l|}{ Medication use } \\
\hline . NSAIDs & $63(9.9)$ & $107(10.3)$ & 0.79 \\
\hline - Coxib & $16(2.5)$ & $22(2.1)$ & 0.60 \\
\hline - Antiplatelet agent & $188(29.5)$ & $362(34.8)$ & 0.03 \\
\hline - Anticoagulant & $72(11.3)$ & $152(14.6)$ & 0.05 \\
\hline - Acetaminophen & $14(2.2)$ & $24(2.3)$ & 0.88 \\
\hline - Corticosteroid & $19(3.0)$ & $66(6.3)$ & 0.002 \\
\hline Extravasation on contrast-enhanced $\mathrm{CT}^{1}$ & $189(29.6)$ & $253(24.3)$ & 0.02 \\
\hline \multicolumn{4}{|l|}{ Stigmata of recent hemorrhage } \\
\hline - Active bleeding ${ }^{2}$ & $373(58.5)$ & $623(60.0)$ & 0.58 \\
\hline - Location, left-sided colon & $190(29.8)$ & $311(29.9)$ & 0.97 \\
\hline \multicolumn{4}{|l|}{ Endoscopic factors } \\
\hline - Early colonoscopy ${ }^{3}$ & $500(78.4)$ & $825(79.3)$ & 0.67 \\
\hline - Bowel preparation, use of PEG solution and/or glycerin enema & $589(92.3)$ & $879(84.4)$ & $<0.001$ \\
\hline - Use of distal attachment & $605(94.8)$ & $923(88.7)$ & $<0.001$ \\
\hline - Use of a water-jet scope & $589(92.3)$ & $926(89.0)$ & 0.02 \\
\hline \multicolumn{4}{|c|}{$\begin{array}{l}\text { NSAID, nonsteroidal anti-inflammatory drug; CT, computed tomography; PEG, polyethylene glycol. Note: data are presented as n (\%). Missing values were as follows } \\
\text { in the band ligation and clipping group: } 27 \text { cases }(4.2 \%) \text { and } 72 \text { cases }(6.9 \%) \text { for "body mass index," } 89(13.9 \%) \text { and } 131(13.5 \%) \text { for "current drinker," } 67(10.5 \%) \text { and } \\
123(11.8 \%) \text { for "current smoker," } 6(0.9 \%) \text { and } 23(2.2 \%) \text { for "systolic blood pressure," } 10(1.6 \%) \text { and } 29(2.8 \%) \text { for "pulse," } 17(2.7 \%) \text { and } 42(4.0 \%) \text { for "albumin," } \\
2(0.3 \%) \text { and } 7(0.7 \%) \text { for "blood urea nitrogen," and } 1(0.2 \%) \text { and } 1(0.1 \%) \text { for "history of colonic diverticular hemorrhage," respectively. } \\
1 \text { Abdominal CT during hospitalization was performed for } 474 \text { patients }(74.3 \%) \text { in the band ligation group and } 698 \text { patients (67.1\%) in the clipping group. Contrast- } \\
\text { enhanced CT was performed in } 397 \text { patients }(62.2 \%) \text { in the band ligation group and } 541 \text { patients }(52.0 \%) \text { in the clipping group. Patients who did not undergo CT } \\
\text { were included in the analysis as having no extravasation on contrast-enhanced CT. } \\
2 \text { In patients with non-active bleeding, a visible vessel was found in } 127(19.9 \%) \text { and } 178 \text { patients }(17.1 \%) \text { in the band ligation and clipping groups, respectively, and } \\
\text { an adherent clot was found in } 143(22.4 \%) \text { and } 249 \text { patients }(23.9 \%) \text { in the respective groups. There was no significant difference in the number of visible vessels or } \\
\text { adherent clots between the two groups. } \\
\text { 3 Early colonoscopy is defined as that performed within } 24 \text { hours of admission. }\end{array}$} \\
\hline
\end{tabular}


- Table 2 Effects of band ligation versus clipping on clinical outcomes.

\begin{tabular}{|c|c|c|c|c|c|c|}
\hline & $\begin{array}{l}\text { Band ligation } \\
(n=638)\end{array}$ & $\begin{array}{l}\text { Clipping } \\
(n=1041)\end{array}$ & $\begin{array}{l}\text { Crude OR } \\
(95 \% \mathrm{Cl})\end{array}$ & $P$ value & $\begin{array}{l}\text { Adjusted OR } \\
(95 \% \mathrm{CI})\end{array}$ & $P$ value \\
\hline $\begin{array}{l}\text { Achievement of initial hemos- } \\
\text { tasis }\end{array}$ & $608(95.3)$ & 994 (95.5) & $0.96(0.60-1.53)$ & 0.86 & $0.91(0.53-1.56)$ & 0.76 \\
\hline \multicolumn{7}{|l|}{ Rebleeding } \\
\hline - Early rebleeding ${ }^{1}$ & $84(13.2)$ & $256(24.6)$ & $0.46(0.36-0.61)$ & $<0.001$ & $0.46(0.34-0.62)$ & $<0.001$ \\
\hline - Late rebleeding ${ }^{2}$ & $173(27.1)$ & $389(37.4)$ & $0.62(0.50-0.77)$ & $<0.001$ & $0.62(0.49-0.79)$ & $<0.001$ \\
\hline \multicolumn{7}{|c|}{ Mortality after endoscopic treatment } \\
\hline - Within 30 days & $1(0.2)$ & $2(0.2)$ & $0.82(0.07-9.01)$ & 0.87 & NA & NA \\
\hline - Within 1 year & $9(1.4)$ & $13(1.3)$ & $1.13(0.48-2.66)$ & 0.78 & NA & NA \\
\hline Thromboembolism & $3(0.5)$ & $9(0.9)$ & $0.54(0.15-2.01)$ & 0.36 & NA & NA \\
\hline - Cardiovascular events & $0(0)$ & $3(0.3)$ & NA & NA & NA & NA \\
\hline - Cerebrovascular events & $3(0.5)$ & $4(0.4)$ & $1.22(0.27-5.49)$ & 0.79 & NA & NA \\
\hline - Pulmonary embolism or DVT & $0(0)$ & $2(0.2)$ & NA & NA & NA & NA \\
\hline Need for IVR & $14(2.2)$ & $50(4.8)$ & $0.44(0.24-0.81)$ & 0.008 & $0.37(0.19-0.76)$ & 0.006 \\
\hline Need for surgery & $4(0.6)$ & $5(0.5)$ & $1.31(0.35-4.89)$ & 0.69 & NA & NA \\
\hline $\begin{array}{l}\text { Red blood cell transfusion } \\
\text { needed }^{3}\end{array}$ & $193(30.3)$ & 351 (33.7) & $0.85(0.69-1.05)$ & 0.14 & $0.97(0.74-1.26)$ & 0.80 \\
\hline $\begin{array}{l}\text { Length of hospital stay after } \\
\text { endoscopic treatment }>7 \text { days }\end{array}$ & 145 (22.7) & $476(45.7)$ & $0.35(0.28-0.44)$ & $<0.001$ & $0.35(0.27-0.45)$ & $<0.001$ \\
\hline \multicolumn{7}{|c|}{$\begin{array}{l}\text { OR, odds ratio; DVT, deep vein thrombosis; IVR, interventional radiology; NA, not applicable. } \\
\text { Note: data are presented as } \mathrm{n}(\%) \text { or median (interquartile range). The multivariate analysis was adjusted for age, sex, and the following } 15 \text { factors that were poten- } \\
\text { tially clinical important variables, most of which were found to have at least borderline significance }(P<0.10) \text { on univariate analysis: current drinker, systolic blood } \\
\text { pressure } \leq 100 \mathrm{mmHg} \text {, loss of consciousness, hemoglobin }<12 \mathrm{~g} / \mathrm{dL} \text {, white blood cell }>10000 / \mu L, \text { blood urea nitrogen }>25 \mathrm{mg} / \mathrm{dL} \text {, antiplatelet use, anticoagulant use, } \\
\text { corticosteroid use, extravasation on computed tomography, location, early colonoscopy, bowel preparation, use of distal attachment, and use of water-jet scope. In } \\
\text { the analysis of IVR need, multivariate analysis was adjusted for age, sex, and four factors found to have significance }(P<0.01) \text { on univariate analysis between the } \\
\text { groups because at least } 10 \text { events per confounder were needed. Outcomes with a smaller number of events were described as NA in multivariate analysis. Outcomes } \\
\text { that included a sample size of zero were excluded from the analysis. } \\
{ }^{1} \text { Early rebleeding is defined as rebleeding within } 30 \text { days of initial hemostasis. } \\
{ }^{2} \text { Late rebleeding is defined as rebleeding within } 1 \text { year of initial hemostasis. } \\
\left.{ }^{3} \text { Units of red blood cell transfused were } 4 \text { ( } 2-6\right) \text { in the band ligation group and } 4(2-6) \text { in the clipping group, among only the patients who required red blood cell } \\
\text { transfusion }(P=0.003) \text {. The mean number of units transfused was } 5.1 \text { in the band ligation group and } 5.7 \text { in the clipping group. } \\
{ }^{4} \text { Length of hospital stay after endoscopic treatment was } 5(4-7) \text { days in the band ligation group and } 7(5-10) \text { days in the clipping group }(P<0.001) \text {. }\end{array}$} \\
\hline
\end{tabular}

ferences in the results when the missing values were imputed using the multiple imputation method (Table $2 \mathbf{s}$ ).

\section{Endoscopic treatment and rebleeding risk according to bleeding type, timing of colonoscopy, and location}

Uni- and multivariate logistic regression models revealed that, relative to clipping, EBL had significantly lower ORs for early and late rebleeding in patients with active bleeding $(P<0.05$; - Table 3). In patients with early colonoscopy, EBL had a significantly lower OR of early and late rebleeding relative to clipping $(P<0.05)$. In patients with non-early colonoscopy, EBL also had a significantly lower OR for early rebleeding, although not for late rebleeding, compared with clipping. The OR of early and late rebleeding after EBL compared with clipping was significantly lower in the right-sided colon $(P<0.05)$, but not in the left-sided colon.

\section{Endoscopically relevant adverse events}

Colonic diverticulitis was identified in one patient $(0.16 \%)$ following EBL and two patients (0.19\%) following clipping $(\triangleright$ Table 4). Colonic perforation developed in two patients $(0.31 \%)$ following EBL, but in none following clipping. No significant differences in AEs were found between the two treatments.

\section{Discussion}

Analysis of our large nationwide dataset for acute hematochezia has revealed detailed baseline characteristics and clinical outcomes relevant to endoscopic therapy for $\mathrm{CDH}$. Notably, we found that EBL significantly lowered both the early and late rebleeding rates after endoscopic treatment for $\mathrm{CDH}$ compared with clipping, regardless of active bleeding or early colonoscopy. Moreover, EBL was associated with less need for IVR and 
- Table 3 Comparison of rebleeding risks between endoscopic band ligation and clipping for colonic diverticular hemorrhage according to type of bleeding (active bleeding vs. non-active bleeding) on colonoscopy, the timing of colonoscopy, and bleed location (right vs. left) in logistic regression models.

\begin{tabular}{|c|c|c|c|c|c|c|}
\hline $\begin{array}{l}\text { Active bleeding } \\
(\mathrm{n}=996)\end{array}$ & $\begin{array}{l}\text { Band ligation } \\
(n=373)\end{array}$ & $\begin{array}{l}\text { Clipping } \\
(\mathrm{n}=623)\end{array}$ & Crude OR (95\%CI) & $P$ value & Adjusted OR (95\%Cl) & $P$ value \\
\hline Early rebleeding ${ }^{1}$ & $53(14.2)$ & $181(29.1)$ & $0.40(0.29-0.57)$ & $<0.001$ & $0.41(0.29-0.57)$ & $<0.001$ \\
\hline Late rebleeding ${ }^{2}$ & $114(30.6)$ & $265(42.5)$ & $0.59(0.45-0.78)$ & $<0.001$ & $0.59(0.45-0.78)$ & $<0.001$ \\
\hline $\begin{array}{l}\text { Non-active bleeding } \\
(n=683)\end{array}$ & $\begin{array}{l}\text { Band ligation } \\
(n=265)\end{array}$ & $\begin{array}{l}\text { Clipping } \\
(n=418)\end{array}$ & Crude OR (95\%CI) & $P$ value & Adjusted OR (95\%Cl) & $P$ value \\
\hline Early rebleeding ${ }^{1}$ & $31(11.7)$ & 75 (17.9) & $0.61(0.39-0.95)$ & 0.03 & $0.69(0.43-1.11)$ & 0.13 \\
\hline Late rebleeding ${ }^{2}$ & $59(22.3)$ & $124(29.7)$ & $0.68(0.47-0.97)$ & 0.03 & $0.69(0.47-1.00)$ & 0.05 \\
\hline $\begin{array}{l}\text { Early colonoscopy } \\
(n=1325)\end{array}$ & $\begin{array}{l}\text { Band ligation } \\
(n=500)\end{array}$ & $\begin{array}{l}\text { Clipping } \\
(\mathrm{n}=825)\end{array}$ & Crude OR (95\%CI) & $P$ value & Adjusted OR (95\%Cl) & $P$ value \\
\hline Early rebleeding ${ }^{1}$ & $73(14.6)$ & $211(25.6)$ & $0.50(0.37-0.67)$ & $<0.001$ & $0.47(0.34-0.66)$ & $<0.001$ \\
\hline Late rebleeding ${ }^{2}$ & $138(27.6)$ & $319(38.7)$ & $0.60(0.48-0.77)$ & $<0.001$ & $0.60(0.46-0.79)$ & $<0.001$ \\
\hline $\begin{array}{l}\text { Non-early colonoscopy } \\
(n=354)\end{array}$ & $\begin{array}{l}\text { Band ligation } \\
(n=138)\end{array}$ & $\begin{array}{l}\text { Clipping } \\
(n=216)\end{array}$ & Crude OR (95\%CI) & $P$ value & Adjusted OR (95\%Cl) & $P$ value \\
\hline Early rebleeding ${ }^{1}$ & $11(8.0)$ & $45(20.8)$ & $0.33(0.16-0.66)$ & 0.002 & $0.35(0.17-0.72)$ & 0.004 \\
\hline Late rebleeding ${ }^{2}$ & $35(25.4)$ & $70(32.4)$ & $0.71(0.44-1.14)$ & 0.16 & $0.79(0.48-1.29)$ & 0.34 \\
\hline $\begin{array}{l}\text { Right-sided colon } \\
(n=1178)\end{array}$ & $\begin{array}{l}\text { Band ligation } \\
(n=448)\end{array}$ & $\begin{array}{l}\text { Clipping } \\
(n=730)\end{array}$ & Crude OR (95\%CI) & $P$ value & Adjusted OR ( $95 \% \mathrm{Cl})$ & $P$ value \\
\hline Early rebleeding ${ }^{1}$ & $48(10.7)$ & $180(24.7)$ & $0.37(0.26-0.52)$ & $<0.001$ & $0.37(0.26-0.53)$ & $<0.001$ \\
\hline Late rebleeding ${ }^{2}$ & $108(24.1)$ & $265(36.3)$ & $0.56(0.43-0.73)$ & $<0.001$ & $0.56(0.42-0.73)$ & $<0.001$ \\
\hline $\begin{array}{l}\text { Left-sided colon } \\
(n=501)\end{array}$ & $\begin{array}{l}\text { Band ligation } \\
(n=190)\end{array}$ & $\begin{array}{l}\text { Clipping } \\
(\mathrm{n}=311)\end{array}$ & Crude OR (95\%CI) & $P$ value & Adjusted OR (95\%Cl) & $P$ value \\
\hline Early rebleeding ${ }^{1}$ & $36(18.9)$ & $76(24.4)$ & $0.72(0.46-1.13)$ & 0.15 & $0.86(0.52-1.41)$ & 0.55 \\
\hline Late rebleeding ${ }^{2}$ & $65(34.2)$ & 124 (39.9) & $0.78(0.54-1.14)$ & 0.21 & $0.89(0.59-1.35)$ & 0.59 \\
\hline
\end{tabular}

$\mathrm{CT}$, computed tomography.

Note: data are presented as $\mathrm{n}(\%)$. Multivariate analysis was adjusted for age, sex, and the factors found to have at least significance $(P<0.05)$ on univariate analysis between the two groups as follows: in a subgroup analysis of active bleeding, blood urea nitrogen $>25 \mathrm{mg} / \mathrm{dL}$, anticoagulant use, bowel preparation, and use of distal attachment; in a subgroup analysis of non-active bleeding, hemoglobin $<12 \mathrm{~g} / \mathrm{dL}$, albumin $<3.0 \mathrm{~g} / \mathrm{dL}$, blood urea nitrogen $>25 \mathrm{mg} / \mathrm{dL}$, corticosteroid use, extravasation on CT, bowel preparation, use of distal attachment, and use of water-jet scope; in a subgroup analysis of early colonoscopy, current drinker, systolic blood pressure $\leq 100 \mathrm{mmHg}$, loss of consciousness, hemoglobin $<12 \mathrm{~g} / \mathrm{dL}$, white blood cell $>10000 / \mathrm{hL}$, blood urea nitrogen $>25 \mathrm{mg} / \mathrm{dL}$, antiplatelet use, anticoagulant use, corticosteroid use, extravasation on CT, bowel preparation, and use of distal attachment; in a subgroup analysis of early colonoscopy, current drinker, systolic blood pressure $\leq 100 \mathrm{mmHg}$, loss of consciousness, hemoglobin $<12 \mathrm{~g} / \mathrm{dL}$, white blood cell $>10000 / \mu \mathrm{l}$, blood urea nitrogen $>25 \mathrm{mg} / \mathrm{dL}$, antiplatelet use, anticoagulant use, corticosteroid use, extravasation on CT, bowel preparation, and use of distal attachment; in a subgroup analysis of non-early colonoscopy, active bleeding, use of distal attachment, and use of water-jet scope; in a subgroup analysis of right-sided colon, systolic blood pressure $\leq 100 \mathrm{mmHg}$, loss of consciousness, blood urea nitrogen $>25 \mathrm{mg} / \mathrm{dL}$, modified Charlson co-morbidity index $\geq 2$, extravasation on CT, bowel preparation, use of distal attachment, and use of water-jet scope; in a subgroup analysis of left-sided colon, current smoker, antiplatelet use, corticosteroid use, and bowel preparation.

${ }^{1}$ Early rebleeding is defined as rebleeding within 30 days of initial hemostasis.

${ }^{2}$ Late rebleeding is defined as rebleeding within 1 year of initial hemostasis.

${ }^{3}$ Early colonoscopy is defined as that performed within 24 hours of admission.

shorter LOS. Both endoscopic treatments achieved high success rates of initial hemostasis, with low rates of death and thromboembolism. Finally, analysis of our large dataset $(n=1679)$ revealed very few AEs related to EBL or clipping, with diverticulitis developing in $0.16 \%(1 / 638)$ and $0.19 \%(2 / 1041)$ of patients, respectively, and colonic perforation in $0.31 \%(2 / 638)$ and $0 \%$ (0/1041) of patients.

This study revealed that EBL was better able to prevent early rebleeding compared with clipping. EBL allows for occlusion of the underlying artery, thereby contributing to the prevention of early rebleeding, whereas the risk of early rebleeding following clipping depends on whether or not the endoclips are placed directly on the visible vessel $[4,9]$. In our experience, even though we usually place multiple endoclips for $\mathrm{CDH}$ with $\mathrm{SRH}$, hemostasis may be difficult to achieve, especially in patients with active bleeding, a small diverticular orifice, or where the site of hemorrhage is at the base of the diverticulum, and early rebleeding may still occur. This led us to hypothesize that EBL would have the advantage of achieving hemostasis and reducing rebleeding compared with clipping in patients with active 
- Table 4 Characteristics and clinical outcomes of patients with endoscopically relevant adverse events for colonic diverticular hemorrhage.

\begin{tabular}{|c|c|c|c|c|c|c|}
\hline \multicolumn{2}{|l|}{ Case number } & 1 & 2 & 3 & 4 & 5 \\
\hline \multicolumn{2}{|l|}{ Age, years } & 79 & 80 & 83 & 60 & 83 \\
\hline \multicolumn{2}{|l|}{ Sex } & Female & Female & Male & Male & Male \\
\hline \multicolumn{2}{|l|}{$\mathrm{BMI}, \mathrm{kg} / \mathrm{m}^{2}$} & 20 & 17 & 23 & 23 & 15 \\
\hline \multicolumn{2}{|c|}{ Current drinker/smoker } & $\mathrm{No} / \mathrm{No}$ & $\mathrm{No} / \mathrm{No}$ & Unknown/No & Yes/Yes & Yes/No \\
\hline \multirow{2}{*}{$\begin{array}{l}\text { Laboratory data } \\
\text { on admission }\end{array}$} & Hemoglobin, g/dL & 7.6 & 11.2 & 12.2 & 9.6 & 8.3 \\
\hline & Albumin, $\mathrm{g} / \mathrm{dL}$ & 2.6 & 4.2 & 3.9 & 3.7 & 2 \\
\hline \multicolumn{2}{|l|}{ Co-morbidities } & $\begin{array}{l}\text { Hypertension, } \\
\text { chronic renal } \\
\text { failure on hemo- } \\
\text { dialysis }\end{array}$ & None & $\begin{array}{l}\text { Hypertension, } \\
\text { diabetes melli- } \\
\text { tus, ischemic } \\
\text { heart disease, } \\
\text { chronic renal } \\
\text { failure }\end{array}$ & $\begin{array}{l}\text { Hypertension, } \\
\text { diabetes melli- } \\
\text { tus, chronic he- } \\
\text { patitis }\end{array}$ & $\begin{array}{l}\text { Hypertension, } \\
\text { diabetes melli- } \\
\text { tus, hyperlipide- } \\
\text { mia, cerebrovas- } \\
\text { cular disease }\end{array}$ \\
\hline \multirow[t]{3}{*}{ Medication } & $\begin{array}{l}\text { Antithrombotic } \\
\text { agent }\end{array}$ & No & No & $\begin{array}{l}\text { Low-dose aspirin, } \\
\text { warfarin }\end{array}$ & Warfarin & Low-dose aspirin \\
\hline & NSAIDs & No & No & No & No & No \\
\hline & Corticosteroid & No & No & No & No & No \\
\hline \multicolumn{2}{|c|}{ Stigmata of recent hemorrhage } & Active bleeding & Active bleeding & Active bleeding & Adherent clot & Adherent clot \\
\hline \multicolumn{2}{|l|}{ Location } & Descending colon & Sigmoid colon & Sigmoid colon & Ascending colon & Ascending colon \\
\hline \multicolumn{2}{|c|}{ Endoscopic treatment } & Band ligation & Band ligation & Clipping & Clipping & Band ligation \\
\hline \multicolumn{2}{|c|}{ Endoscopically relevant adverse event } & Perforation & Perforation & Diverticulitis & Diverticulitis & Diverticulitis \\
\hline \multicolumn{2}{|c|}{$\begin{array}{l}\text { Time until adverse event after endo- } \\
\text { scopic treatment, days }\end{array}$} & 5 & 4 & 1 & 3 & 4 \\
\hline \multicolumn{2}{|c|}{ Treatment for adverse event } & Surgery & Surgery & $\begin{array}{l}\text { Conservative } \\
\text { therapy }\end{array}$ & $\begin{array}{l}\text { Conservative } \\
\text { therapy }\end{array}$ & $\begin{array}{l}\text { Conservative } \\
\text { therapy }\end{array}$ \\
\hline
\end{tabular}

bleeding. As we hypothesized, EBL did significantly decrease the rate of early and late rebleeding relative to clipping, regardless of active bleeding.

Additionally, EBL also reduced the rate of late rebleeding in this study, consistent with the finding of previous small cohort studies [4,23]. Because scar formation at the previous treatment site is observed in most patients and the diverticulum itself disappears after ligation [4,23], rebleeding from the same diverticulum treated with EBL theoretically cannot occur, so EBL may prevent late rebleeding as well as early rebleeding. However, we often have $\mathrm{CDH}$ patients who experience repeated bleeding in the long term, with rebleeding often occurring at a site different from the previously treated one [4]. Regrettably, in this study, we could not confirm whether rebleeding was from the original site. Most patients have multiple diverticula, and increasing numbers of patients have various risk factors for $\mathrm{CDH}$ (e.g. advanced age, obesity, arteriosclerotic disease, and medication use) [24]. Taken together, it appears that endoscopic hemostasis alone is not enough to prevent rebleeding in the long term. Therefore, in addition to effective endoscopic treatment, the rebleeding risk should be reduced by, for exam- ple, avoiding the administration of antithrombotic agents or NSAIDs.

Consistent with previous studies, the need for IVR was lower with EBL than with clipping [10]. We believe that this reduction in rebleeding during hospitalization following EBL led to the reduced need for IVR, which in turn probably led to the shorter LOS seen with EBL. Indeed, the association between rebleeding and need for IVR was found to be significant in the entire CODE BLUE-J study population $[15,16]$. In contrast, the number of patients needing surgery, developing thromboembolism, or dying was too small to reach statistical significance between the two treatments.

Most reports on endoscopic treatment for $\mathrm{CDH}$ have focused on effectiveness, and limited data exist regarding procedure-related AEs because of their rarity. However, clarifying the rates of $A E s$ is important in determining treatment strategy and providing appropriate information for informed consent. In this study, the endoscopically relevant AEs were diverticulitis $(0.18$ $\%$ ) with each treatment and perforation (0.12\%) with EBL. To date, diverticulitis after clipping has not been reported, while two cases have been reported after EBL $[4,25]$. Mechanical tissue damage following an endoscopic procedure causes an ulcer 
to form on the intestinal mucosa, which assists in the invasion of gut commensal bacteria and may lead to local colonic inflammation. In relation to endoscopy treatment-related perforation, we should consider the potential risk of delayed perforation following hemostasis with the ligation method because of the absence of the muscular layer in the colonic diverticulum [26-28]. The incidence of colonic perforation is generally estimated to be $0 \%-0.33 \%$ for whole therapeutic colonoscopies ( $n=74630$ ) [29], suggesting that our result of $0.12 \%$ in $\mathrm{CDH}$ treatment is not so high compared with other endoscopic treatments.

We acknowledge that this study has some limitations. First, this was not a randomized controlled trial. Such trials are challenging to conduct in the emergency setting of acute lower gastrointestinal bleeding because of the lengthy time they would take to complete [30]. Second, endoscopic clipping was not classified as direct or indirect placement in this study, and we plan to compare the effectiveness of these two methods in a separate study. Third, we could not consider the time period of endoscopic devices such as new clips or EBL in the analysis because we could not obtain detailed information on the prevalence of each treatment method at each institution.

The strengths of our study include the very large number of cases analyzed $(n=1679)$ and few missing data values $[15,16]$. This large long-term dataset enabled us to make a detailed analysis of baseline characteristics, endoscopic information, and SRH type and location, which are all factors that may affect clinical outcome, but which have not been examined fully in previous studies. Moreover, we could evaluate the long-term rebleeding and mortality rates after endoscopic therapy for $\mathrm{CDH}$.

In conclusion, this nationwide multicenter cohort study revealed the effectiveness and $A E s$ related to endoscopic therapy for $\mathrm{CDH}$. EBL had the advantages of both lower early and late rebleeding rates, reduced need for IVR, and shortened LOS. Our findings can offer patients and physicians useful information on the safety and effectiveness of endoscopic therapy and help in the selection of endoscopic treatment technique for diverticular hemorrhage.

\section{Acknowledgments}

The authors thank Kazuyo Jo, Shiho Kamimura, Sanae Habu, Akiko Takamatsu, Minako Kajihara, and Kenko Yoshida for their help with the data collection and analysis. Additionally, the authors thank the members of Tokyo Metropolitan Bokutoh Hospital for their valuable contribution to data collection. We are grateful to Koichi Shirakawa for his statistical advice.

\section{Funding}

\section{JSPS KAKENHI Grant 20K08366}

Smoking Research Foundation, Takeda Science Foundation, Grantsin-Aid for Research from the National Center for Global Health and Medicine 19A-2015

the Ministry of Health, Labour and Welfare 19HB1003

\section{Competing interests}

The authors declare that they have no conflict of interest.

\section{References}

[1] Nagata N, Ishii N, Manabe N et al. Guidelines for colonic diverticular bleeding and colonic diverticulitis: Japan Gastroenterological Association. Digestion 2019; 99: (Suppl. 01): 1-26

[2] Jensen DM, Ohning GV, Kovacs TOG et al. Natural history of definitive diverticular hemorrhage based on stigmata of recent hemorrhage and colonoscopic Doppler blood flow monitoring for risk stratification and definitive hemostasis. Gastrointest Endosc 2016; 83: 416-423

[3] Kaise M, Nagata N, Ishii $\mathrm{N}$ et al. Epidemiology of colonic diverticula and recent advances in the management of colonic diverticular bleeding. Dig Endosc 2020; 32: 240-250

[4] Nagata N, Ishii N, Kaise M et al. Long-term recurrent bleeding risk after endoscopic therapy for definitive colonic diverticular bleeding: band ligation versus clipping. Gastrointest Endosc 2018; 88: 841853.e4

[5] Okamoto N, Tominaga N, Sakata Y et al. Lower rebleeding rate after endoscopic band ligation than endoscopic clipping of the same colonic diverticular hemorrhagic lesion: a historical multicenter trial in Saga, Japan. Intern Med 2019; 58: 633-638

[6] Honda H, Ishii N, Takasu A et al. Risk factors of early rebleeding in the endoscopic management of colonic diverticular bleeding. J Gastroenterol Hepatol 2019; 34: 1784-1792

[7] Kobayashi K, Furumoto Y, Akutsu D et al. Endoscopic detachable snare ligation improves the treatment for colonic diverticular hemorrhage. Digestion 2020; 101: 208-216

[8] Kaltenbach T, Watson R, Shah J et al. Colonoscopy with clipping is useful in the diagnosis and treatment of diverticular bleeding. Clin Gastroenterol Hepatol 2012; 10: 131-137

[9] Kishino T, Kanemasa K, Kitamura Y et al. Usefulness of direct clipping for the bleeding source of colonic diverticular hemorrhage (with videos). Endosc Int Open 2020; 8: E377-E385

[10] Nagata N, Niikura R, Ishii $\mathrm{N}$ et al. Cumulative evidence for reducing recurrence of colonic diverticular bleeding using endoscopic clipping versus band ligation: systematic review and meta-analysis. J Gastroenterol Hepatol 2020: doi:10.1111/jgh.15370

[11] Niikura R, Nagata N, Doyama H et al. Current state of practice for colonic diverticular bleeding in 37 hospitals in Japan: A multicenter questionnaire study. World J Gastrointest Endosc 2016; 8: 785-794

[12] Farrell J], Graeme-Cook F, Kelsey PB. Treatment of bleeding colonic diverticula by endoscopic band ligation: an in-vivo and ex-vivo pilot study. Endoscopy 2003; 35: 823-829

[13] Ikeya T, Ishii N, Nakano K et al. Risk factors for early rebleeding after endoscopic band ligation for colonic diverticular hemorrhage. Endosc Int Open 2015; 3: E523-E528

[14] Shibata S, Shigeno T, Fujimori K et al. Colonic diverticular hemorrhage: the hood method for detecting responsible diverticula and endoscopic band ligation for hemostasis. Endoscopy 2014; 46: 66-69

[15] Nagata N, Kobayashi K, Yamauchi A et al. Nationwide large-scale data of acute lower gastrointestinal bleeding in Japan uncover detailed etiologies and relevant outcomes: CODE BLUE J-Study. medRxiv 2021: doi:10.1101/2021.01.18.21250035

[16] Nagata N, Kobayashi K, Yamauchi A et al. Identifying bleeding etiologies by endoscopy affected outcomes in 10,342 cases with hematochezia: CODE BLUE-J Study. Am J Gastroenterol 2021; 116: 22222234 
[17] Charlson ME, Pompei P, Ales KL et al. A new method of classifying prognostic comorbidity in longitudinal studies: development and validation. J Chronic Dis 1987; 40: 373-383

[18] de'Angelis N, Di Saverio S, Chiara O et al. 2017 WSES guidelines for the management of iatrogenic colonoscopy perforation. World J Emerg Surg 2018; 13: 5

[19] van de Wall BJM, Draaisma WA, van der Kaaij RT et al. The value of inflammation markers and body temperature in acute diverticulitis. Colorectal Dis 2013; 15: 621-626

[20] Peduzzi P, Concato ], Kemper E et al. A simulation study of the number of events per variable in logistic regression analysis. J Clin Epidemiol 1996; 49: 1373-1379

[21] Kenward MG, Carpenter J. Multiple imputation: current perspectives. Stat Methods Med Res 2007; 16: 199-218

[22] van Buuren S. Multiple imputation of discrete and continuous data by fully conditional specification. Stat Methods Med Res 2007; 16: 219242

[23] Nakano K, Ishii N, Ikeya T et al. Comparison of long-term outcomes between endoscopic band ligation and endoscopic clipping for colonic diverticular hemorrhage. Endosc Int Open 2015; 3: E529-E533
[24] Kinjo K, Matsui T, Hisabe T et al. Increase in colonic diverticular hemorrhage and confounding factors. World J Gastrointest Pharmacol Ther 2016; 7: 440-446

[25] Ishii N, Fujita Y. Colonic diverticulitis after endoscopic band ligation performed for colonic diverticular hemorrhage. ACG Case Rep J 2015; 2: $218-220$

[26] Tominaga N, Ogata S, Esaki M. Rare complication of endoscopic band ligation for colonic diverticular bleeding. JGH Open 2020; 4: 12441245

[27] Sato Y, Yasuda H, Fukuoka A et al. Delayed perforation after endoscopic band ligation for colonic diverticular hemorrhage. Clin J Gastroenterol 2020; 13: 6-10

[28] Takahashi S, Inaba T, Tanaka N. Delayed perforation after endoscopic band ligation for treatment of colonic diverticular bleeding. Dig Endosc 2016; 28: 484

[29] Panteris V, Haringsma J, Kuipers E]. Colonoscopy perforation rate, mechanisms and outcome: from diagnostic to therapeutic colonoscopy. Endoscopy 2009; 41: 941-951

[30] Laine L, Shah A. Randomized trial of urgent vs. elective colonoscopy in patients hospitalized with lower GI bleeding. Am J Gastroenterol 2010; 105: 2636-2641 quiz 2642 